\title{
Does XBRL Adoption Imporve Information Asymmetry? Evidence from Taiwan Public Companies
}

\author{
Tzu-Yi F ${ }^{1 *}$, Fengyi $L^{2}$, Shih-Hsuan $C^{2}$ and Kwo-Liang $\mathrm{C}^{3}$
}

${ }^{1}$ Department of Political Science, Fu Hsing Kang College, National Defense University, Taiwan

${ }^{2}$ Department of Business Management, National Taipei University of Technology, Taiwan

${ }^{3}$ Information Technology Division, Small and Medium Enterprise Administration, Ministry of Economic Affairs, Taiwan

\begin{abstract}
This paper examines whether or not XBRL (eXtensible Business Reporting Language) adoption reduces information asymmetry in Taiwan's Public companies. Recently, XBRL and International Financial Reporting Standards (IFRS) have gradually received substantial attention in the accounting field and the international capital market. Users of financial information can analyze and convert financial reports into the same format by using XBRL. This study evaluated whether XBRL adoption reduced information asymmetry. Prior scholars have used bid-ask spread as a proxy variable of information asymmetry to explore whether XBRL adoption reduced information asymmetry. This study focused on information asymmetry in Taiwan's capital market. In addition to using bid-ask spread as a proxy variable of information asymmetry, we used stock turnover ratio and earnings volatility as proxy variables for measuring the level of information asymmetry.
\end{abstract}

The results of this study demonstrated that XBRL adoption significantly affects the information-asymmetry proxy variables and that effectively reduce information asymmetry in Taiwan's capital market. Based on these findings, the government should promote the XBRL usages in financial reporting and require XBRL adoption by all public companies to enable financial information users XBRL.

Keywords: Extensible business reporting language (XBRL); Information asymmetry; Bid-ask spread; Turnover rate; Stock return volatility

\section{Introduction}

\section{Research background and purposes}

The eXtensible Business Reporting Language (XBRL) adoption in financial reporting has been expected to be one of the most important changes in the disclosure environment [1]. It is also expected to bring significant benefits to the capital market [2].This study explored whether information asymmetry in Taiwan's stock exchange market was reduced after the government required that all public companies in Taiwan report financial information using the eXtensible Business Reporting Language (XBRL) format in September 2010. In the globalized capital market, investors have the demands regarding the types of financial information disclosed in financial reports by domestic and foreign enterprises have increased. However, the accounting standards employed for financial reporting vary among countries, resulting in numerous financial report formats and styles. These differences create difficulties for international investors when analyzing financial reports generated in various countries. Therefore, standardizing financial report formats among countries is beneficial for investors worldwide.

Based on current trends, many countries have gradually conformed to the International Financial Reporting Standards (IFRS) created by International Accounting Standards Board (IASB). Taiwan has also positively responded to this adoption. The Financial Supervisory Commission, R.O.C invited relevant organizations to formulate a promotion plan for implementing the IFRS. XBRL International Inc. established a set of financial reporting format standards that can be applied internationally, which requires the standardization of information e-communication languages among different enterprises, namely XBRL [3]. Numerous countries have implemented XBRL, including China, Japan, Spain, and South Korea. After Taiwan adopted
IFRS, the International Accounting Standards Board (IASB) developed XBRL taxonomy standards in compliance with IFRS requirements. Therefore, enterprises now report or disclose financial information according to the XBRL taxonomy standards that were introduced in the IFRS.

To establish an information disclosure system that conforms to international standards, Taiwan has also promoted XBRL successfully, using the efforts of relevant personnel and organizations. XBRL is an application of eXtensible Markup Language (XML) in corporate information reporting and disclosure. XML is a declaration language that enables instant conversion between online information and application programs or devices. XBRL is an application of XML used in financial information exchange. It can be used to report financial statements and express detailed financial information. These functions involve using relevant accounting concepts. The full name of XBRL is eXtensible Business Reporting Language. The "eXtensible" in XBRL represents the flexibility of XBRL, which can be programmed by users according to specific needs. "Business" represents that XBRL manages information in the business field. "Reporting" identifies that XBRL can be used to report business data, such as net income of the current period and advertising costs. Parties that require this information (e.g., investors, analysts, enterprise divisions, and managers) can obtain data

*Corresponding author: Tzu-Yi F, Department of Political Science, Fu Hsing Kang College, National Defense University, Taiwan, Tel: +886-2-2895-4012; E-mail: brianfang0427@gmail.com

Received December 01, 2015; Accepted January 19, 2016; Published January 22, 2016

Citation: Tzu-Yi F, Fengyi L, Shih-Hsuan C, Kwo-Liang C (2016) Does XBRL Adoption Imporve Information Asymmetry ? Evidence from Taiwan Public Companies. J Glob Econ 4: 172. doi:10.4172/2375-4389.1000172

Copyright: @ 2016 Tzu-Yi F, et al. This is an open-access article distributed under the terms of the Creative Commons Attribution License, which permits unrestricted use, distribution, and reproduction in any medium, provided the original author and source are credited. 
access by using XBRL. "Language" denotes that XBRL is a standardized Internet and computer markup language used to annotate enterprise data, thereby facilitating the meaningful recognition and reception of these data by various software applications to satisfy the diverse demands of the parties who require these data.

Recently, XBRL has attracted international attention and numerous experts have conducted studies on XBRL. Alles and Piechocki examined the effectiveness of XBRL in improving corporate governance and found that using XBRL enables stakeholders to obtain various perspectives of information, thereby contributing to diverse decisions; however, XBRL does not guarantee absolute or necessary decisions. Therefore, XBRL offers additional information that is valuable and enables investors to make informed decisions. Premuroso and Bhattacharya explored whether early and voluntary adopters of XBRL for generating financial reports exhibited enhanced corporate governance performance [4]. Their results indicated that enterprise performance factors (e.g., liquidity and company size) were correlated with whether enterprises voluntarily filed financial reports using the XBRL format.

Diamond and Verrecchia claimed that information asymmetry decreases when information disclosure increases, thereby providing additional data to investors and enabling informed decision making of stock investments [5]. When large investors desire to invest in more shares, the liquidity of enterprise shares rises and enterprise capital costs decrease. As XBRL adopt information disclosure levels increase, information asymmetry tends to decline. This phenomenon reduces capital costs and enhances evaluations regarding enterprises. XBRL also enables investors in the capital market to analyze information using novel methods, compare enterprise performances, acquire standardized information, and identify previously unanalyzed enterprises. Regarding corporate organizational systems, if all companies used XBRL to disclose financial information, superior information exchange between enterprises can be achieved, and the overall enterprise accounting system improved. This is because XBRL facilitates effective business management by overcoming software and system limitations and eliminating data barriers.

Concerning the accounting industry, Lin predicted that when accounting firms disclose their financial information online, they would face online data verification requirements. One advantage of using XBRL is that manual methods are not required to interpret data programmed in various formats; instead, standard application programs can be used to directly acquire the disclosed financial data of enterprises. If XBRL can be further connected to the standardized audit trail database of enterprises and effective control and system logic are ensured, continuous data verification could be conducted online directly. This operational model largely reduces manual operation and enhances verification efficiency and quality. Chan inferred that several XBRL characteristics, such as structuralization and reusability, could adequately improve accountant auditing efficiency.

If enterprises use the XBRL format to report financial information, investors would obtain numerous benefits. Some argued that using the XBRL format in reporting financial information enhances corporate information transparency in capital markets; this topic has received substantial attention from investors. When enterprises report highquality financial information in a standardized format, investors tend to believe that investment in these enterprises possesses low risk and offers high returns. This conviction can eventually reduce capital costs and increase enterprise stock prices. Therefore, reporting financial information in the XBRL format is vital for public companies especially because the level of information disclosure typically influences investor decisions.

This study examined whether XBRL adoption by Taiwan's public companies would increase the extent of their information disclosure and reduce information asymmetry among investors. Taiwan is one of the leading countries that have developed a mandatory filing program in XBRL format. This policy has been in effect in Taiwan since September 2010, thus the Taiwan stock market is an appropriate target market to investigate the initial effect of XBRL adoption.

\section{Literature Review}

\section{Corporate information disclosure and information asymmetry}

In recent years, several scandals and scams regarding the activities of the business enterprises have occurred around the globe. The financial scandals at Enron, WorldCom, Tyco, Olympus, and others have showed corporate governance weaknesses and have increased the awareness of investors and scholars similar in various governance and accounting transparency issues. Some of the governance weaknesses stem from the information asymmetry between insiders and the investing public. One way to mitigate the information asymmetry problem is to enhance accounting disclosures through the adoption of XBRL format [6].

Information asymmetry causes inefficiencies in the capital market. Prior literature found that inadequate enterprise information disclosure and information asymmetry is closely correlated. Information asymmetry occurs when one party in a business transaction possesses increased or superior information compared with that of the other party. Frankel and Li declared that the U.S. Securities Exchange Act was enacted to reduce information asymmetry in the 1934 U.S capital market [7]. Benston stated that the Securities Exchange Act of 1934 required information disclosure to establish a capital market of fairness and high efficiency [8].

Information disclosure is both a voluntary and compulsory activity that refers to the provision of corporate performance and governance information to external investors. In addition, information disclosure is a core element of capital market efficiency. When various stakeholders can closely analyze the same financial information (e.g., financial statements and notes and the discussions, analyses, and forecasts of enterprise managers), efficiency is enhanced in the capital market. Government agencies require public companies to disclose financial information to increase capital market efficiency and enterprises provide information to investors to enable informed investment decision making.

One perceived benefit of XBRL is to improve efficiency and accessibility so that financial analysts can incorporate more data into their analysis and follow more companies [9]. Benston asserted that fairness is meaningful and vital in the capital market and all investors should have equal access to corporate financial information [8]. Lev stated that relevant legal provisions should be enacted to reduce capital-market information asymmetry by mandating enterprise financial-information disclosure [10]. Diamond and Verrecchia argue that if firms increase the level of disclosures, the level of information asymmetry is decreased [5]. Yoon et al. examine whether or not XBRL adoption reduces information asymmetry in the Korean stock market. Using t-tests and multiple regression analysis in their study, they find a significant reduction of the information asymmetry for large firms in the Korean stock market [11]. Efendi, Park, et al., Efendi, Smith, et al. 
find that XBRL reports have incremental information content beyond HTML reports as evidenced by price reaction when XBRL reports are published [12,13]. Using the sample of XBRL mandatory filings by Yoon et al. and Kim et al. demonstrate that XBRL mandatory filings significantly mitigate information asymmetry in the capital market $[11,14]$.

\section{XBRL}

XBRL is the product of XBRL International (www.xbrl. org), a nonprofit consortium of more than 450 global financial service, technology, stock exchange, government, and accounting organizations. XBRL has become an international standard for addressing the challenging issues that businesses and governments face worldwide in current financial reporting and regulation XBRL is a standardized type of XML that is used to enhance the efficiency, reliability, and accuracy of financial reporting [15]. It is expected to benefit all members of the financial information supply chain by making information exchangeable between different applications and systems and easy for users to extract, search, and reuse [16,17]. Data in the XBRL format do not require conversion among application programs due to XBRL utilizes standardized labels on data items, which facilitates independence between data and application programs. The XBRL format supports financial and non-financial data. This function is one difference between XBRL and traditional financial reporting programming languages. The use of standardized labels on data in the XBRL format enables users to specifically identify, automatically convert, and extract reliable financial information from different application programs.

Many businesses, regulators, and investors can benefit from $\mathrm{XBRL}$, because it standardizes various financial reporting formats, thereby integrating the reporting processes of different enterprises, lowering the costs of compliance to reporting specifications and of quality assurance services, and facilitating communication between enterprises and financial markets. By acquiring, integrating, processing, and reporting different financial information using the same format, $\mathrm{XBRL}$ assists investors in receiving operational reports of various companies. In addition, implementing XBRL in enterprises reduces the costs of corporate information acquisition and of adhering to various regulations regarding international financial reporting.

With the adoption of XBRL, financial information can be optimized for machine creation, automation, release, discovery, consumption, and reuse. XBRL enhances communication efficiency among investors by providing them with an information supply chain of corporate financial reports. For example, financial information in the XBRL format possesses enhanced integration efficiency and outcomes. In addition, the information flow between raw material suppliers and logistics companies is simplified by this improved efficiency in the supply chain.

The data-search enhancement function of XBRL is applicable for seeking various types of financial information. This function assists investors in forming investment decisions. Both novice and experience investors can easily search and compare data items that share identical or similar labels. Hodge claimed that although financial report notes are important, they are difficult for beginner investors to analyze comprehensively because beginners lack relevant financialinformation experience and knowledge. This problem is solved by the XBRL-enhanced data search engine [2].

The tags of XBRL provide additional information to investors because these labels explain the meaning of data items. Russo stated that data should be presented in formats that render the information useful and meaningful and provided empirical results indicating that information presented in a standardized format improves user decision-making abilities [18]. Hodge used Russo's results to analyze and compare different accounting approaches in enterprises and found that XBRL users could easily differentiate various accounting approaches; for example, XBRL-enhanced search mechanisms so as to improve financial-report transparency [2]. Pinsker and Li, indicates that additional XBRL benefits include lowers costs by enhancing enterprise data processing abilities, reducing data duplication, increasing operational efficiency, and reducing bookkeeping costs [19]

\section{XBRL in Asia}

Background: Investor demands for financial information are increasing in current globalized capital markets. Because various countries have specific accounting standards and enterprises disclose financial information online using diverse formats or styles, data reuse and analysis processes are complex. However, investors worldwide urgently desire compatibility among global financial reports.

To achieve the goal of international financial report compatibility, two steps must first be performed. First, all countries must implement the same accounting standards. Increasing numbers of countries have gradually conformed to the IFRS. Financial Supervisory Commission, R.O.C. invited relevant organizations to formulate a promotion plan for IFRS adoption. Second, financial reporting standards that can be universally applied must be established (i.e., corporate information requires a standardized e-communication language). XBRL was created to satisfy this requirement. The promotion of XBRL has become a global trend and Taiwan has endorsed the adoption of XBRL by using the efforts of relevant personnel and organizations. To establish a universal information disclosure system, Taiwan must promote XBRL adoption to enterprises regarding financial reporting. However, XBRL adoption among Taiwan's enterprises has been slow. Chou asserted that before 2005, only several studies had examined the development of XBRL adoption in Taiwan. Compared with other counties (e.g., South Korea) where the development of XBRL adoption has been increasing systematically, efficiently, and rapidly, XBRL adoption in Taiwan is extremely slow. In August 2005, after recognizing the importance of XBRL in national infrastructure, the team of the Department of Engineering and Applied Science, National Science Council (NSC) that evaluates interdisciplinary integration projects subsidized a large-scale, 3 -year research plan for promoting XBRL adoption in Taiwan.

XBRL adoption plans in Asian countries: China was the first country in Asia that mandated enterprise adoption of XBRL for financial reporting. The China Securities Regulatory Commission enforced XBRL adoption primarily because the extensibility of XBRL can benefit China by facilitating information exchange and sharing with other countries. In addition, other countries, such as South Korea and Japan, have been promoting XBRL adoption. These countries have mandated that all public companies start using XBRL to report their financial information within a certain period. The National Tax Agency of Japan now requires that enterprises use XBRL to file income tax since the financial reporting taxonomy standards were announced on July 4, 2003. The Bank of Japan began implementing XBRL in its financial audit system on February 8, 2006. The Financial Services Agency of Japan also stipulated that the corporate financial reporting taxonomy standards for EDINET, Japan's electronic disclosure system, adopt the XBRL2.1 format. The XBRL-enabled consolidated annual accounts taxonomy standards announced by the Tokyo Stock Exchange (TSE) 
apply to the following industries: general, banking, insurance, and stock industries. The content of the taxonomy standards involves operational performance, financial conditions, cash flow conditions, consolidated subsidiary companies, the number of enterprises to which equity laws are applicable, and performance forecasts of the current fiscal year. To promote the taxonomy standards, the TSE gathered and converted the data of 33 enterprises to the XBRL format for 3 fiscal years.

In 2006, the Financial Services Commission of South Korea started promoting XBRL by encouraging enterprises to voluntarily implement XBRL. In November 2007, filing financial reports in XBRL became compulsory. Currently, all public companies in South Korea have adopted XBRL for financial reporting, thereby facilitating investors in analyzing public-company financial data. The English version of these XBRL-formatted financial reports is available for foreign investors. Taiwan is also promoting XBRL adoption.

Taiwan's XBRL adoption plan can be divided into three stages. At the first stage, a demonstration platform was established. The financial reports of 77 public companies were converted into the XBRL format to provide investors with reference information. At the second stage, voluntary adoption was encouraged through a voluntary filing program; this involved XBRL adoption for the following four major financial statements: balance sheets, income statements, statements of changes in shareholder equity, and cash flow statements. Beginning in May 2010, the government encouraged public companies to voluntarily file their 2009 and first-quarter 2010 financial reports using XBRL. The third stage involved mandating XBRL adoption, including the four major financial statements, accountant audit reports, and financial statement notes. The government required that all public companies begin reporting their financial statements in XBRL by September 30, 2010. Therefore, concerning XBRL adoption, Taiwan lags behind countries, such as China, South Korea, and Japan. To accelerate XBRL adoption for financial reporting in Taiwan's capital market, a taskforce for promoting XBRL adoption by public companies for financial reporting was formed to conduct research and convene discussions on relevant issues. This group was under the supervision of the Financial Supervisory Commission, R.O.C. and contained representatives from the Taiwan Stock Exchange, Gre Tai Securities Market, Accounting Research Development Foundation, various industrial and commercial organizations, as well as accountant representatives, scholars, and experts.

\section{Research hypotheses}

XBRL adoption extends investor abilities for locating information, thereby reducing information asymmetry in the capital market. XBRL facilitates these positive changes because XBRL improves information quality without increasing information quantity. XBRL enhances the flow of information, which is vital for democratizing capital markets. Timely and transparent financial reports and data disclosed in the XBRL format reduce enterprise capital costs. Pinsker and Li stated that XBRL adoption is correlated with the increase of financial-report information transparency [19]. Hodge et al. claimed that beginner investors tend to use XBRL-enhanced search engines for information acquisition rather than consulting professional financial analysts [2]. Hunton and McEwen asserted that most financial analysts that provide accurate forecasts search for information directly, whereas analysts providing inaccurate forecasts search for information sequentially [20]. Therefore, information-seeking strategies and forecasting accuracy are theoretically correlated. Frederickson and Miller declared that professional financial analysts tend to use well-defined valuation models and nonprofessional investors tend to use valuation models that are poorly defined or heuristic [21]. However, because the XBRL taxonomy standards and labels equip users with powerful and direct capabilities in seeking and analyzing information, nonprofessional investors can analyze the obtained enterprise financial reports based on their needs, rather than relying on professional financial analysts.

In capital markets, increases in enterprise information disclosure reduce information asymmetry (Diamond \& Verrecchia) and using the XBRL format to report enterprise financial information improves information transparency and quality [5]. Both experienced and beginner investors benefit from using XBRL-enhanced search mechanisms. According to prior study results, enterprise XBRL adoption could reduce capital-market information asymmetry by raising the information disclosure level of enterprises. To measure information asymmetry, Yoon et al. examined whether XBRL adoption in the South Korean stock market reduced information asymmetry effectively [11]. They used bid-ask spread as a proxy variable of information asymmetry. Their results indicated that after XBRL adoption, bid-ask spread became substantially lower in the South Korean stock market. This demonstrated that XBRL adoption lowered information asymmetry in the South Korean stock market. Prior literature has also found that regardless of whether enterprise information disclosure was voluntarily or mandatory, the level of information asymmetry in the capital market remained the same. For example, the disclosures of both fragmented information and current petroleum and gas prices were correlated with a reduced bid-ask spread. Schrand and Verre stated that information disclosure levels regarding the initial public offering of an enterprise are negatively correlated with bid-ask spread [22]. Leuz and Verrecchia compared two German markets. One market exhibited high information disclosure (i.e., the Neuer Market) and the other exhibited low information disclosure (i.e., the Frankfurt Exchange) [23]. Their results illustrated that compared with stocks in the Frankfurt Exchange, those in the Neuer Market exhibited lower bid-ask spread and higher liquidity.

Therefore, in addition to using the Taiwan stock market as the sample, we adopted three information asymmetry indicators as proxy variables: bid-ask spread, stock turnover ratio and earnings volatility $[23,24]$. We propose three hypotheses corresponding to the three proxy variables to measure information asymmetry.

H1: When other conditions remain the same, enterprises that have adopted XBRL exhibit a low bid-ask spread.

$\mathrm{H} 2$ : When other conditions remain the same, enterprises that have adopted XBRL present a high stock turnover ratio.

$\mathrm{H} 3$ : When other conditions remain the same, enterprises that have adopted XBRL possess low earnings volatility.

\section{Research Method}

This study explored whether XBRL adoption in enterprises reduced information asymmetry in the capital market. The study sample was public companies in Taiwan's stock market primarily because these companies have been reporting financial information in the XBRL format since October 2010. In this section, we explain the data collection process and analysis methods that were used to measure information asymmetry.

\section{Information asymmetry measures}

Information asymmetry is an abstract concept that is difficult to observe; thus, it cannot be used directly as a variable. Therefore, to explore the influence of XBRL on information asymmetry, proxy 
variables must be used to represent information asymmetry. This study employed the three most widely used information asymmetry variables of previous studies as the dependent variables: bid-ask spread, stock turnover ratio, and earnings volatility $[23,24]$.

The bid-ask spread refers to the difference between the quoted buyer and seller prices of a stock. In the United States, bid-ask spread is the price difference that market makers sets regarding the shares outstanding in the stock exchange. The bid prices (the stock prices at which dealers wish to purchase) that are established by dealers are the ask prices for investors and the ask prices (the stock prices at which dealers wish to sell) that are established by dealers are the bid prices for investors. The difference between these prices is the bidask spread. Bid-ask spread involves profits for dealers and additional transaction costs for investors and is composed of three dealer-related costs: order processing, inventory carrying, and adverse selection. In addition to order processing costs and inventory-carrying costs, bidask spread in the United States also refers to the risks of information asymmetry that are predicted by dealers. Although these risks only occur between dealers and investors, information asymmetry is caused by non-transparent information regarding the outstanding shares of enterprises. Numerous studies and theories continue to use bid-ask spread as a proxy variable for information asymmetry. Although bidask spread is one of the most widely used proxy variables of information asymmetry by previous studies, the transaction mechanism in Taiwan's capital market is different from that of the U.S. market $[23,24]$. Thus, the definitions of bid-ask spread in these two markets differ. The bidask spread in Taiwan is determined by the orders made by two parties to a transaction; the spread is not decided by dealers. The disclosed bid price in stock markets refers to the highest bid price offered by buyers in the latest centralized matchmaking transaction. Conversely, the disclosed ask price refers to the highest ask price that sellers are willing to accept in the latest centralized matchmaking transaction. The balance between these two prices is the bid-ask spread of stocks in Taiwan's stock market. Several empirical studies in Taiwan have claimed that the disclosed bid-ask spread can be used as a proxy variable for information asymmetry. However, we used the daily closing bid price and closing ask price instead of the basic transaction prices for the bid-ask spread variable.

Boone studied the Accounting Series Release (ASR) 253 (SEC, 1978) provision in the ASR published by the U.S. Securities and Exchange Commission (SEC) and suggested that the initial disclosure of the discounted present value of oil and gas reserves was associated with a decline in the bid-ask spread of enterprises' common stocks, which persisted for 1 year following the initial price disclosure $[25,26]$. This finding is significant because ASR 253 provides investors with equal access to information, thus enhancing the fairness of the capital market. Boone used bid-ask spread as the proxy variable of information asymmetry for examining whether ASR 253 effectively reduces information asymmetry. We adopted the approach by Boone and used bid-ask spread as a proxy variable of information asymmetry, which can be computed using the following formula [25]:

$$
\text { Relative Spread }=\frac{\text { Ask price }- \text { Bid price }}{\frac{\text { Ask price }+ \text { Bid price }}{2}}
$$

Stock turnover ratio refers to the turnover of an enterprise divided by the total number of its stocks within a certain period. Similar to turnovers, turnover ratio reflects the level of trading activity. Trading activity is negatively correlated with information asymmetry. Stocks with high trading activity levels possess high liquidity, attract new investors, and can increase vital information that is reflected in the stock prices. Stock turnover ratio is negatively correlated with bid-ask spread.

Earnings volatility refers to the degree of fluctuation in the interest rate for a stock within a certain period. When the information asymmetry level among investors is high, stock prices fluctuate drastically. Leuz et al. stated that low earnings volatility indicates low information asymmetry [23]. Previous studies have shown that stock earnings volatility is positively correlated with bid-ask spread. In quotedriven markets, earnings volatility reflects the degree of uncertainty or risk. In markets where earnings volatility is high, market makers may use the high bid-ask spread to compensate for risk $[23,24]$.

Leuz et al. explored whether increasing the information disclosure level of enterprises could effectively reduce information asymmetry. They inferred that earnings volatility is the least reliable proxy variable among the three proxy variables (i.e., bid-ask spread, stock turnover ratio, and earnings volatility) for information asymmetry because earnings volatility is influenced by factors other than information asymmetry [23]. Among these influencing factors, information disclosure exerts a complex effect on earnings volatility and is associated with various types of institutional investors. In addition, among the three proxy variables, bid-ask spread is the most used and appropriate variable for measuring information asymmetry. Although transaction numbers and price fluctuations are both correlated with information asymmetry, factors other than information asymmetry also affect transaction numbers and price fluctuations. Clarke and Shastri conducted an empirical study that compared various proxy variables used to measure information asymmetry and asserted that compared with variables, such as analyst forecasts and investment opportunity sets, variables representing the market microstructure (e.g., bid-ask spread) measure information asymmetry with increased accuracy [27]. Aitken et al. and Stoll also recommended using bid-ask spread as a proxy variable for information asymmetry $[28,29]$. In addition, the bid-ask spread in quote-driven markets (e.g., the TSE, Paris Bourse, and Korea Stock Exchange) differs from that of order-driven markets (e.g., Taiwan's stock market). Therefore, bid-ask spread can be used as an indicator of information asymmetry in Taiwan's stock market. We used these three information-asymmetry proxy variables and developed the following three models.

Binary variables of XBRL: We used multiple regression analysis to analyze whether XBRL adoption reduces information asymmetry. Information asymmetry was used as the dependent variable and the three models were developed using bid-ask spread, turnover ratio and earnings volatility. XBRL adoption was the primary explanatory variable in the regression models. Other factors, such as insider shareholding, the number of forecasts that analysts performed, research and development (R\&D) expenses, stock prices, and enterprise size were considered control variables primarily because these factors are also closely correlated with information asymmetry. In addition, as the dependent variable in the second model, turnover ratio was used as a control variable in the bid-ask spread and earnings volatility models. Control variables were used in all three models to explain information asymmetry variability. XBRL adoption was the dummy variable. Preand post-adoption stages were set to 0 and 1 , respectively.

Variables influencing information asymmetry: The turnover ratio can be calculated by dividing the daily turnover by the number of shares outstanding. Similar to turnover, turnover ratio also reflects the trading activity level [30]. Stocks demonstrating high levels of trading activity possess increased liquidity and are more likely to reflect key 
information in the stock prices. Consequently, turnover ratio is negatively correlated with bid-ask spread [11]. Previous studies have also claimed that when the transaction number (turnover ratio) is high and enterprise size is small, earnings volatility is high [23].

Prior studies have indicated that R\&D-intensive high-tech companies tend to possess high levels of information asymmetry and that capitalization of $\mathrm{R} \& \mathrm{D}$ can reduce information asymmetry because by capitalizing $\mathrm{R} \& \mathrm{D}$, managers can transmit information regarding the anticipated profit from the R\&D to investors. Managers may convey this information voluntarily by using other methods; however, managers restrict the amount of voluntarily disclosed information because excessive disclosure can cause the cost to surpass the profit yielded by low information asymmetry. Therefore, when R\&D expenses remain unacknowledged, voluntary information disclosure does not reduce information asymmetry. In addition, in a study exploring the correlation between R\&D expenses and information asymmetry, Mohd used bid-ask spread and turnover ratio as the proxy variables of information asymmetry to examine whether high-tech companies possessed higher information asymmetry than other companies [24]. The researchers discussed the relationship between $R \& D$ expenses and earnings volatility (the third proxy variable of information asymmetry) and hypothesized that $\mathrm{R} \& \mathrm{D}$ expenses and earnings volatility were positively correlated; thus, when R\&D expenses increased, information asymmetry also increased.

Concerning insider shareholding, Cheng and Lo asserted that insiders strategically select disclosure methods to maximize trading profits. Moverover, when managers plan to purchase shares, they release negative information to reduce purchase prices. To study the relationship between conference calls and information asymmetry, Brown et al. adopted insider shareholding ratio as the control variable [31]. The data contained direct and indirect shareholdings of the board of directors, executives, and management authorities. This study adopted the insider shareholder definition by Chang et al. which divided insider shareholders into three categories: directors, supervisors, and large shareholders who owned more than $10 \%$ of the enterprise shares. Accordingly, the insider shareholding ratio in this study constitutes the shareholding ratios of directors, supervisors, managers, and large shareholders who owned more than $10 \%$ of the shares.

Brown et al. stated that insider shareholding is positively correlated with bid-ask spread and negatively correlated with turnover ratio [31]. In addition to bid-ask spread and turnover ratio, they used earnings volatility as a proxy variable of information asymmetry. When earnings volatility increases, information asymmetry increases. This study explored the influence of insider shareholding on earnings volatility based on the assumption that insider shareholding is positively correlated with earnings volatility.

The relationship between the number of analyst forecasts and information asymmetry is complex. Ayers et al. and Piotroski and Roulstone inferred that when analysts produce numerous forecasts, investors with access to private information tend to increase their transactions. Brown et al. and Easley et al. claimed that the number of analyst forecasts is positively correlated with the total number of uninformed transactions [31,32]. In addition, Frankel et al., and Easley et al. declared that the number of earnings forecasts that analysts produce is negatively correlated with information asymmetry $[7,31,32]$. Therefore, an increased production of forecasts regarding earnings indicates low information asymmetry. The present study assumes that the number of earnings forecasts produced by analysts is negatively correlated with bid-ask spread and turnover ratio. Therefore, when enterprises disclose increased information, analysts tend to produce more earnings forecasts, thereby lowering information asymmetry.

Concerning stock prices, several researchers have stated that stock prices are positively correlated with bid-ask spread; however, others have contended that the correlation is negative [24,33-36]. Therefore, the relationship between stock prices and bid-ask spread is unclear because markets containing high information asymmetry challenge investors to accurately evaluate enterprise performance. The present study examined the relationship between stock prices and information asymmetry (i.e., the relationship between stock prices and the three proxy variables of information asymmetry: bid-ask spread, turnover ratio, and earnings volatility).

We used the natural logarithm of operating income to measure enterprise size. Based on previous studies, enterprise size is negatively correlated with information asymmetry [23,32,35,37,38]. Large companies possess low bid-ask spread because they provide increased information to market participants. When financial report users have access to relevant information, they make improved decisions relating to buying or selling stocks at reasonable prices. In addition, large enterprises typically engage in increased trading activity and receive enhanced attention from the mass media and investment analysts. Thus, the information asymmetry level of large enterprises is generally lower than that of small enterprises. We assume that enterprise size is negatively correlated with bid-ask spread, positively correlated with turnover ratio, and negatively correlated with earnings volatility.

\section{Data}

In October 2010, the government required that all public companies in Taiwan report financial information in the XBRL format (TSEC Regulations, Legal Interpretative Letter No. 0990007770). Since 2012, public companies could voluntarily implement the IFRS early and adopt the XBRL format to report financial information; therefore, these companies may report financial information using the XBRL taxonomy standards introduced in the IFRS. To explore the influence of XBRL adoption on Taiwan's public companies, the preadoption period was set to be between December 2007 and August 2008, and the post-adoption period was set to be between October 2010 and June 2011. These target periods were selected based on three factors. First, Taiwan began mandating that public companies file financial reports in the XBRL format since September 2010. Second, XBRL adoption in Taiwan is gradually advancing. In December 2008, the financial statements of 77 public companies were converted from their original formats to the XBRL format. This action provided a demonstration platform and financial analysis tools for investors. The voluntary filing program began at the end of May 2010. During this period, not all public companies reported their financial information in the XBRL format and the data of companies that voluntarily filed financial reports in XBRL was difficult to obtain. Therefore, the period between December 2008 and September 2010 was excluded from this study. Third, the period from September 2008 to December 2008 was also excluded primarily because several major U.S. investment banks went bankrupt during the global financial crisis and this began to substantially affect Taiwan's financial market beginning in September of 2008. Consequently, the period after September 2008 was not included in the pre-adoption period. In addition, the financial crisis exerted a negative influence on Taiwan's stock market. Thus, the 9 months between December 2007 and August 2008 were used as the pre-adoption period. Another reason for excluding the period between September 2008 and December 2008 is that we used earnings volatility as a proxy variable of information asymmetry (dependent variable). 
Citation: Tzu-Yi F, Fengyi L, Shih-Hsuan C, Kwo-Liang C (2016) Does XBRL Adoption Imporve Information Asymmetry ? Evidence from Taiwan Public Companies. J Glob Econ 4: 172. doi:10.4172/2375-4389.1000172

Page 7 of 11

Earnings volatility can be calculated by using the standard deviation of stock interest rate and drastic fluctuations in stock prices can cause deviations in the measured earnings volatility.

This study inspected the transaction data of common stocks in public companies. Transaction data listing bid prices or ask prices of 0 were excluded. We obtained the data from the Taiwan Economic Journal; these transaction data contained 642 public companies from 19 industries.

\section{Findings}

\section{Descriptive statistics}

Table 1 presents the descriptive statistics analysis results of all the variables during the pre- and post-adoption periods. Overall, 642 enterprises from 19 industries were included in both the pre- and post-adoption periods, rendering 1,284 overall. Based on the results presented in Table 1, the average bid-ask spread during the postadoption period (0.0043) was lower than that of the pre-adoption period (0.0068), and the earnings volatility during the post-adoption period (1.9221) was lower than that of the pre-adoption period (2.9147). These two results support $\mathrm{H} 1$ and $\mathrm{H} 3$. By contrast, the turnover ratio in the post-adoption period (0.6754) was lower than that of the preadoption period (0.7075), which does not support H2. However, other variables (e.g., XBRL adoption, enterprise size, turnover ratio, stock price, insider shareholding, the number of earnings forecasts produced by analysts, and R\&D expenses) could have affected the increase in turnover ratio. In addition, the average stock price in the postadoption period (37.8467) was higher than that of the pre-adoption period (34.7446). Enterprise size was measured by applying the natural logarithm of operating income. The average enterprise size was 8.2748 in the pre-adoption period and 8.2703 in the post-adoption period.

\section{Correlation coefficient analysis}

Table 2 shows the Pearson correlation coefficients of the study variables. According to these results, no correlation coefficients between any two variables were over 0.7 , which indicates that considerable correlations did not occur. Bid-ask spread and earnings volatility were significantly and negatively correlated with XBRL adoption (i.e., after XBRL was implemented, bid-ask spread and earnings volatility decreased). Turnover ratio was non-significantly and negatively correlated with XBRL adoption, which contradicted H2. In addition, bid-ask spread was significantly and negatively correlated with turnover ratio (i.e., when bid-ask spread was high, turnover ratio was low, suggesting high information asymmetry; and vice versa). Therefore, the relationship between bid-ask spread and turnover ratio conforms to our assumptions. Inside shareholding was significantly and negatively correlated with turnover ratio $(-0.375)$ and the number of earnings forecasts produced by analysts was significantly and positively correlated with turnover ratio $(0.178)$; that is, when insider shareholding was high and analyst forecasts low, the turnover ratio was low. Enterprise size and turnover ratio were significantly and negatively correlated (i.e., the turnover ratio in large enterprises was

\begin{tabular}{|c|c|c|c|c|c|c|c|c|}
\hline \multicolumn{5}{|c|}{ Pre-adoption period } & \multicolumn{4}{|c|}{ Post-adoption period } \\
\hline variable & Min & Max & Mean & S.D. & Min & Max & Mean & S.D \\
\hline Bid-ask spread & 0.0016 & 0.08692 & 0.0068 & 0.0093 & 0.0013 & 0.0914 & 0.0043 & 0.0063 \\
\hline Turnover & 0.0080 & 6.2987 & 0.7075 & 0.6925 & 0.0029 & 3.9083 & 0.6754 & 0.5917 \\
\hline Volatility & 1.0824 & 6.0751 & 2.9147 & 0.7384 & 0.4926 & 5.8815 & 1.9221 & 0.6223 \\
\hline Inside & 10.2411 & 94.3844 & 42.6329 & 16.1818 & 7.8733 & 94.4167 & 42.5455 & 16.2145 \\
\hline Analyst & 0 & 86 & 5.57 & 10.421 & 0 & 89 & 3.79 & 8.833 \\
\hline Rea & 0.0000 & 451.1900 & 3.3277 & 18.4342 & -0.405 & 195.5800 & 3.3462 & 10.8629 \\
\hline Stock price & 1.4625 & 656.6467 & 34.7446 & 47.1706 & 2.5963 & 980.1141 & 37.8467 & 60.4973 \\
\hline Size & 2.3264 & 18.2659 & 8.2748 & 4.7142 & 2.0635 & 18.0421 & 8.2703 & 4.7299 \\
\hline
\end{tabular}

Note : ${ }^{* * *}$ : level of significant is $1 \%, * *$ : level of significant is $5 \%, *:$ level of significant is $10 \%$.

Table 1: Descriptive statistics.

\begin{tabular}{|c|c|c|c|c|c|c|c|c|c|}
\hline & XBRL & Bid-ask spread & Turnover & Volatility & Inside & Analyst & Rea & Stock price & Size \\
\hline XBRL & 1 & & & & & & & & \\
\hline $\begin{array}{l}\text { Bid-ask } \\
\text { spread }\end{array}$ & $\begin{array}{l}-0.157^{* *} \\
(0.000)\end{array}$ & 1 & & & & & & & \\
\hline Turnover & $\begin{array}{l}-0.025 \\
(0.372)\end{array}$ & $\begin{array}{l}-0.245^{\star *} \\
(0.000)\end{array}$ & 1 & & & & & & \\
\hline Volatility & $\begin{array}{l}-0.588^{* *} \\
(0.000)\end{array}$ & $\begin{array}{l}0.400^{* *} \\
(0.000)\end{array}$ & $\begin{array}{l}0.397^{\star *} \\
(0.000)\end{array}$ & 1 & & & & & \\
\hline Inside & $\begin{array}{l}-0.003 \\
(0.932)\end{array}$ & $\begin{array}{l}0.255^{\star *} \\
(0.000)\end{array}$ & $\begin{array}{l}-0.375^{\star *} \\
(0.000)\end{array}$ & $\begin{array}{l}-0.03 \\
(0.291)\end{array}$ & 1 & & & & \\
\hline Analyst & $\begin{array}{l}-0.092^{* *} \\
(0.001)\end{array}$ & $\begin{array}{l}-0.167^{* *} \\
(0.000)\end{array}$ & $\begin{array}{l}0.178^{* *} \\
(0.000)\end{array}$ & $\begin{array}{l}0.120^{* *} \\
(0.000)\end{array}$ & $\begin{array}{l}-0.125^{\star *} \\
(0.000)\end{array}$ & 1 & & & \\
\hline Rea & $\begin{array}{l}0.001 \\
(0.983)\end{array}$ & $\begin{array}{l}0.007 \\
(0.808)\end{array}$ & $\begin{array}{l}0.033 \\
(0.244)\end{array}$ & $\begin{array}{l}0.061^{*} \\
(0.028)\end{array}$ & $\begin{array}{l}-0.104^{* *} \\
(0.000)\end{array}$ & $\begin{array}{l}0.011 \\
(0.704)\end{array}$ & 1 & & \\
\hline Stock price & $\begin{array}{l}0.029 \\
(0.306)\end{array}$ & $\begin{array}{l}-0.138^{* *} \\
(0.000)\end{array}$ & $\begin{array}{l}0.144^{* *} \\
(0.000)\end{array}$ & $\begin{array}{l}0.030 \\
(0.286)\end{array}$ & $\begin{array}{l}0.031 \\
(0.261)\end{array}$ & $\begin{array}{l}0.555^{\star \star} \\
(0.000)\end{array}$ & $\begin{array}{l}0.036 \\
(0.196)\end{array}$ & 1 & \\
\hline Size & $\begin{array}{l}0.000 \\
(0.986)\end{array}$ & $\begin{array}{l}0.002 \\
(0.942)\end{array}$ & $\begin{array}{l}-0.121^{\star *} \\
(0.000)\end{array}$ & $\begin{array}{l}-0.083^{* *} \\
(0.003)\end{array}$ & $\begin{array}{l}0.306^{\star *} \\
(0.000)\end{array}$ & $\begin{array}{l}-0.123^{* *} \\
(0.000)\end{array}$ & $\begin{array}{l}-0.129^{\star *} \\
(0.000)\end{array}$ & $\begin{array}{l}-0.116^{\star *} \\
(0.000)\end{array}$ & 1 \\
\hline
\end{tabular}

Table 2: Correlation coefficient analysis. 
low). Stock prices and turnover ratio were significantly and positively correlated (i.e., when enterprise stock prices were high, turnover ratio was high and information asymmetry was low), which conformed to our assumptions. Bid-ask spread was significantly and negatively correlated with the number of analysts' earnings forecasts and stock prices (i.e., when analysts generated increased forecasts of earnings and stock prices were high, bid-ask price was low, thereby reducing information asymmetry). Bid-ask spread was positively correlated with insider shareholding; therefore, when insider shareholding was high, bid-ask spread was high, and thus information asymmetry was high. These findings all conformed to our study assumptions.

\section{The relationship between XBRL adoption and information asymmetry}

This study used bid-ask spread, turnover ratio, and earnings volatility as the proxy variables of information asymmetry to measure information asymmetry. A high bid-ask spread, low turnover ratio, and high earnings volatility lead to high information asymmetry.

The binary variables of XBRL and proxy variables of information asymmetry: Table 3 presents the results of the three regression analyses introduced in Section 3. The variance inflation factor (VIF) values of these three regression analyses did not exceed 10, indicating that collinearity is not a major concern between the independent variables and the dependent variables. The binary regression variables of XBRL (i.e., the main explanatory variables) were used to explore whether bid-ask spread decreased, turnover ratio increased, and earnings volatility decreased after XBRL adoption. The results indicated that the binary regression variables of XBRL were significantly and negatively correlated with bid-ask spread and earnings volatility (the coefficients were -0.167 and -0.593 , respectively, and both reached a $1 \%$ significance level). This result indicated that after XBRL adoption, both bid-ask spread and earnings volatility were reduced, thereby decreasing information asymmetry. These results supported $\mathrm{H} 1$ and $\mathrm{H} 3$, as well as the findings of previous studies pertaining to $\mathrm{H} 1$ [11]. However, in the turnover ratio model, the negative correlation between the binary regression variables of XBRL and turnover ratio was not significant (the regression coefficient was -0.024). After XBRL adoption, turnover ratio decreased and information asymmetry increased, which did not support $\mathrm{H} 2$, potentially because stock turnover and interest rates are closely related. Stock turnover ratio was calculated by dividing turnover by the number of outstanding shares and earnings volatility was calculated by using the standard deviation of stock interest rates. Exploring the relationship between information asymmetry and enterprise information disclosure levels, Leuz and Verrecchia controlled the variable of earnings volatility in the turnover ratio model and found that turnover ratio and earnings volatility was positively correlated [23]. Other previous studies also presented similar findings. Therefore, earnings volatility is a key variable when modeling stock turnover ratio. We controlled earnings volatility in the turnover ratio model and explored whether XBRL adoption reduced information asymmetry. However, when conducting regression analysis on the total sample, earnings volatility was not controlled. Hence, we conducted additional assessments and the results are presented in later sections. In these subsequent assessments, earnings volatility was controlled in the turnover ratio model before multiple regression analysis was conducted to examine the influence of XBRL adoption by Taiwan's public companies on information asymmetry.

Variables that influence information asymmetry: In the regression analyses that involved using bid-ask spread to measure information asymmetry, we controlled turnover ratio, insider shareholding, the number of earnings forecasts, R\&D expenses, stock prices, and enterprise size. Bid-ask spread was significantly and negatively correlated with turnover ratio, number of earnings forecasts, and enterprise size (the regression coefficients were -0.150 , -0.097 , and -0.102 , respectively, and all reached a $1 \%$ significance level). These results supported the study assumptions and the results of several previous studies Easley et al., 1998; Yoon et al., 2010) [11,30,32] thereby indicating that with high turnover ratios, high numbers of earnings forecasts, and larger company sizes, information asymmetry is reduced. The negative correlation between stock prices and bidask spread was significant (the regression coefficient was -0.078 and reached a 5\% significance level), which supported several previous studies [35]. Accordingly, high stock prices are associated with reduced bid-ask spread, which suggests lowered information asymmetry. Insider shareholding was significantly and positively correlated with bid-ask spread (the regression coefficient was 0.222 and reached a $1 \%$ significance level), which agreed with the results of Brown et al. [31]. Consequently, high insider trading and shareholding cause high information asymmetry. The R\&D expenses were positively but nonsignificantly correlated with bid-ask spread. Therefore, high R\&D expenses indicated high bid-ask spread. This finding supported our assumptions.

In regression analysis involving using turnover ratio to measure information asymmetry, the control variables included insider shareholding ("Inside"), forecast numbers regarding earnings ("Analyst"), R\&D expenses ("Rea"), stock prices ("Stockprice"), and

\begin{tabular}{|c|c|c|c|c|c|c|c|c|c|c|c|c|}
\hline \multirow{3}{*}{ Dependent Variable } & & \multirow{2}{*}{\multicolumn{3}{|c|}{$\begin{array}{c}\text { Model } 1 \\
\text { Bid-ask spread }\end{array}$}} & & \multirow{2}{*}{\multicolumn{3}{|c|}{$\begin{array}{c}\text { Model } 2 \\
\text { Turnover }\end{array}$}} & & \multirow{2}{*}{\multicolumn{3}{|c|}{$\begin{array}{l}\text { Model } 3 \\
\text { Volatility }\end{array}$}} \\
\hline & & & & & & & & & & & & \\
\hline & & & & VIF & & & & VIF & & & & VIF \\
\hline XBRL & - & $-0.167^{\star * \star}$ & $(0.000)$ & 1.019 & + & -0.024 & $(0.354)$ & 1.019 & - & $-0.593^{* * *}$ & $(0.000)$ & 1.019 \\
\hline Turnover & - & $-0.150^{\star * *}$ & $(0.000)$ & 1.203 & & & & & + & $0.491^{* \star *}$ & $(0.000)$ & 1.203 \\
\hline Inside & + & $0.222^{\star \star *}$ & $(0.000)$ & 1.315 & - & $-0.377^{\star * *}$ & $(0.000)$ & 1.144 & + & $0.112^{* * *}$ & $(0.000)$ & 1.315 \\
\hline Analyst & - & $-0.097^{* * *}$ & $(0.002)$ & 1.521 & + & $0.061^{*}$ & $(0.052)$ & 1.516 & - & -0.013 & $(0.572)$ & 1.521 \\
\hline Rea & + & 0.026 & $(0.329)$ & 1.024 & - & -0.010 & $(0.703)$ & 1.023 & + & $0.050^{* * *}$ & $(0.006)$ & 1.024 \\
\hline Stockprice & $+/-$ & $-0.078^{\star *}$ & $(0.015)$ & 1.516 & + & $0.125^{\star \star \star}$ & $(0.000)$ & 1.497 & - & -0.024 & $(0.287)$ & 1.516 \\
\hline Size & - & $-0.102^{* * *}$ & $(0.000)$ & 1.135 & + & 0.015 & $(0.593)$ & 1.134 & - & $-0.038^{* *}$ & $(0.046)$ & 1.135 \\
\hline $\mathrm{R}^{2}$ & & 0.146 & & & & 0.169 & & & & 0.580 & & \\
\hline Adj- $R^{2}$ & & 0.142 & & & & 0.165 & & & & 0.578 & & \\
\hline $\mathrm{N}$ & & 1286 & & & & 1286 & & & & 1286 & & \\
\hline
\end{tabular}

Table 3: Multiple regression analysis. 
enterprise size ("Size"). The results indicated that earnings forecast number was significantly and positively correlated with turnover ratio (the regression coefficient was 0.061 and reached a $10 \%$ significance level). In other words, increased earnings forecasts indicated a high turnover ratio and low information asymmetry. This result supported our assumptions and that of several previous studies [23,31]. Stock prices were significantly and positively correlated with turnover ratio (the regression coefficient was 0.125 and reached a $1 \%$ significance level). Consequently, enterprises possessing high stock prices also possessed high turnover ratios and low information asymmetry. Insider shareholding was significantly and negatively correlated with turnover ratio (the regression coefficient was -0.377 and reached a $1 \%$ significance level). When insider shareholding increased, turnover ratio reduced, and information asymmetry increased. This result corresponded with our assumptions and that of Brown et al. [31]. R\&D expenses were negatively but non-significantly correlated with turnover ratio (the regression coefficient was -0.010 and the significance coefficient was $0.703)$. The study assumption was supported and the results suggested that enterprises possessing high R\&D expenses also exhibited high information asymmetry. In addition, these results supported those of several previous studies, which stated that $\mathrm{R} \& \mathrm{D}$-intensive enterprises possessed high information asymmetry. Enterprise size was positively but non-significantly correlated with turnover ratio (the regression coefficient was 0.015 and the significance coefficient was 0.593). Thus, large enterprises possessed high turnover ratios, and low information asymmetry.

In regression analysis, we use earnings volatility ("Volatility") to measure information asymmetry, the control variables comprised turnover ratio ("Turnover"), insider shareholding, earnings forecast numbers, R\&D expenses, stock prices, and enterprise size. Turnover ratio, insider shareholding, and R\&D expenses were all significantly and positively correlated with earnings volatility (the regression coefficients were $0.491,0.112$, and 0.050 , respectively, and reached a $1 \%$ significance level). The relationship between turnover ratio and earnings volatility corresponded with the results and correlation directions of several previous studies [23]. The relationship of earnings volatility with insider shareholding and R\&D expenses supported our assumptions. Accordingly, high insider shareholding and $\mathrm{R} \& \mathrm{D}$ expenses indicated high earnings volatility, and thus substantial information asymmetry. Enterprise size was significantly and negatively correlated with earnings volatility (the regression coefficient was -0.038 and reached a $5 \%$ significance level). Consequently, large enterprises possessed low earnings volatility, and thus low information asymmetry. This result supported the findings of several previous studies and our assumptions $[23,32,35,37,38]$. Therefore, large enterprises tend to provide increased financial information to investors, thus assisting investors with making decisions regarding stock buying and selling.

Leuz and Verrecchia used earnings volatility as a variable in the turnover ratio model to explore the relationship between earnings volatility and information asymmetry [23]. We also used earnings volatility as a variable in the turnover ratio model and found that when earnings volatility was employed as a variable in the turnover ratio model, the explanatory variable (i.e., XBRL adoption) and turnover ratio were significantly and positively correlated (the regression coefficient was 0.374 and reached a $1 \%$ significance level). Thus, when XBRL was implemented, turnover ratio increased and information asymmetry decreased, thereby corresponding with $\mathrm{H} 2$. The control variables involved insider shareholding, the number of earnings forecasts, R\&D expenses, stock prices, enterprise size, and newly added earnings volatility. Both insider shareholding and R\&D expenses were significantly and negatively correlated with turnover ratio (respectively, the regression coefficients were -0.328 and -0.040 and reached $1 \%$ and $10 \%$ significance levels). Accordingly, when insider shareholding and $\mathrm{R} \& \mathrm{D}$ expenses increased, turnover ratio decreased, thereby increasing information asymmetry. This result corresponded with that of several previous studies and our assumptions. Furthermore, the number of earnings forecasts was significantly and positively correlated with turnover ratio (the regression coefficient was 0.050 and reached a $10 \%$ significance level). Consequently, when the number of analyst forecasts increased, turnover ratio increased, and thus information asymmetry decreased; this result corresponded with that of several previous studies $[7,31,32]$. Enterprise size was positively but non-significantly correlated with turnover ratio (the regression coefficient was 0.035 ). Therefore, large enterprises typically possess high turnover ratios and low information asymmetry. This result corresponded with that of previous studies $[23,32,35,37,38]$. Stock prices were significantly and positively correlated with turnover ratio (the regression coefficient was 0.100 and reached as $1 \%$ significance level). In other words, enterprises possessing high stock prices tend to also have high turnover ratios and thus low information asymmetry. Earnings volatility, the newly added variable, was significantly and positively correlated with turnover ratio (the regression coefficient was 0.659 and reached a $1 \%$ significance level). This result supported that of Leuz and Verrecchia [23]. Therefore, when earnings volatility was added to the turnover ratio model as a variable, both its relationship with turnover ratio and the significance corresponded to our assumptions and the explanatory power increased from $16.5 \%$ to $43.5 \%$. Therefore, earnings volatility was a key variable in the turnover ratio model. When investigating the turnover ratio model, earnings volatility should be controlled to ensure reliable study results (Table 4 ).

\section{Conclusion and Implications}

Taiwan Stock Exchange mandated that public companies in Taiwan file financial statements by using the XBRL format in September 2010. This requirement was a revolutionary transformation for Taiwan's stock market and investors. XBRL adoption assists investors in analyzing the financial reports provided by public companies and facilitates informed decision making based on this information. Whether these aims have been achieved remains to be determined. XBRL adoption can raise the information disclosure level of enterprises. Studies on accounting, finance, and economics have indicated that increased information disclosure levels of enterprises lower information asymmetry in the stock market. Numerous experts have asserted that XBRL adoption can enhance the financial reporting transparency and quality of enterprises; thus, information asymmetry is expected to reduce. This study explored the relationship between XBRL adoption and information asymmetry in Taiwan's stock market.

This study examined whether XBRL adoption reduced information asymmetry in Taiwan's stock market and collected data from 643 public companies in Taiwan's stock market. These data were used to compare information asymmetry levels, which were measured according to bidask spread, turnover ratio, and earnings volatility. The collected data contained information from before and after XBRL was adopted. The results showed that XBRL adoption reduced information asymmetry in Taiwan's stock market and enhanced information comparability by reducing the time and costs of calculating enterprise data (i.e., integrating data from various corporate information systems). XBRL adoption also enhanced XBRL-enabled search mechanisms and the calculation abilities of enterprises by increasing the information transparency and quality in the capital market. In addition, XBRL 


\begin{tabular}{|c|c|c|c|c|c|c|c|c|}
\hline \multirow{3}{*}{$\begin{array}{c}\text { Dependent } \\
\text { Variable }\end{array}$} & \multirow[b]{3}{*}{$\begin{array}{l}\text { The expected } \\
\text { direction }\end{array}$} & \multirow{2}{*}{\multicolumn{3}{|c|}{$\begin{array}{c}\text { Model } 2 \\
\text { (Original Model) } \\
\text { Turnover }\end{array}$}} & \multirow[b]{3}{*}{$\begin{array}{l}\text { The expected } \\
\text { direction }\end{array}$} & \multirow{2}{*}{\multicolumn{3}{|c|}{$\begin{array}{c}\text { Model } 4 \\
\text { (Volatility is control variable) } \\
\text { Turnover }\end{array}$}} \\
\hline & & & & & & & & \\
\hline & & & & VIF & & & & VIF \\
\hline XBRL & + & -0.024 & $(0.354)$ & 1.019 & + & $0.374^{\star * \star}$ & $(0.000)$ & 1.608 \\
\hline Inside & - & $-0.377^{\star * *}$ & $(0.000)$ & 1.144 & - & $-0.328^{\star * *}$ & $(0.000)$ & 1.153 \\
\hline Analyst & + & $0.061^{* *}$ & $(0.052)$ & 1.516 & + & $0.050^{*}$ & $(0.055)$ & 1.517 \\
\hline Rea & - & -0.010 & $(0.703)$ & 1.023 & - & $-0.040^{*}$ & $(0.063)$ & 1.027 \\
\hline Stockprice & + & $0.125^{\star * *}$ & $(0.000)$ & 1.497 & + & $0.100^{* * *}$ & $(0.000)$ & 1.500 \\
\hline Size & + & 0.015 & $(0.593)$ & 1.134 & + & 0.035 & $(0.116)$ & 1.136 \\
\hline Volatility & & & & & + & $0.659^{* * *}$ & $(0.000)$ & 1.612 \\
\hline $\mathrm{R}^{2}$ & & 0.170 & & & & 0.438 & & \\
\hline Adj-R ${ }^{2}$ & & 0.165 & & & & 0.435 & & \\
\hline $\mathrm{N}$ & & 1286 & & & & 1286 & & \\
\hline
\end{tabular}

Table 4: The regression analysis of the model of turnover (Volatility is control variable).

adoption facilitated the information disclosure process of enterprises, which also reduced information asymmetry in the capital market.

The empirical results indicated that when enterprises implemented XBRL, information asymmetry decreased. The multiple regression analysis results of the three models support the study hypotheses. The nine control variables were enterprise size, turnover ratio, earnings volatility, stock prices, insider shareholding, the number of forecasts analysts made regarding earnings, $\mathrm{R} \& \mathrm{D}$ expenses, and industry category. These variables were used to explain information asymmetry in Taiwan's stock market. The primary variable (i.e., XBRL adoption) exhibited a significant correlation with the three proxy variables of information asymmetry, thereby supporting our assumptions. The results indicated that when XBRL was implemented, bid-ask spread and earnings volatility were reduced and turnover ratio rose, thereby reducing information asymmetry. Regarding Taiwan's stock market, the correlations between the control variables and information asymmetry supported the findings of previous studies.

Our paper contributes along several dimensions. First, evidence of the benefits from XBRL adoption was illustrated by examining the Taiwan's Public companies. The effect of XBRL on reducing information asymmetry enhances the quality of valuation for firms and decreases capital cost. These findings can be an empirical and theoretical foundation to accelerate the adoption of XBRL in other countries. Second, our findings provide insight into the impact of a new innovation in information technology on the relation between disclosure and its effect on the heterogeneity in investors' information sets. Finally, we contribute to the emerging literature examining the role of technology in firms' communications with investors.

\section{References}

1. Debreceny R, Farewell S, Piechocki M, Felden C, Graning A (2010) Does it add up? Early evidence on the data quality of XBRL filings to the SEC. J Accoun Public Policy 29: 296-306.

2. Hodge FD, Kennedy JJ, Maines LA (2004) Does search-facilitating technology improve the transparency of financial reporting? Account Rev 79: 687-703.

3. XBRL International (2002) White Paper.

4. Premuroso RF, Bhattacharya S (2008) Do early and voluntary filers of financial information in XBRL format signal superior corporate governance and operating performance? Int J Account Inf Syst 9: 1-20.
5. Diamond DW, Verrecchia RE (1991) Disclosure, liquidity, and the cost of capital. J Finance 46: 1325-59.

6. Ragothaman S (2012) Voluntary xbrl adopters and firm characteristics: an empirical analysis. Int J Digital Account Res 12: 93-119.

7. Frankel R, Li X (2004) Characteristics of a firm's information environment and the information asymmetry between insiders and outsiders. J Account Econ 37: 229-259.

8. Benston GJ (1973) Required disclosure and the stock market: an evaluation of the Securities Exchange Act of 1934. Am Econ Rev 63: 132-155.

9. Baldwin AA, Trinkle BS (2011) The impact of XBRL: A Delphi investigation. In J Digit Account Res 11: 1-24.

10. Lev B (1988) Toward a theory of equitable and efficient accounting policy. Account Rev 63: 1-22.

11. Yoon H, Zo H, Ciganek AP (2010) Does XBRL adoption reduce information asymmetry? J Bus Res 62: 157-163.

12. Efendi J, Park J, Subramaniam C (2010) Do XBRL Reports have incrementa information content? An empirical analysis. Social Sciences Research Work.

13. Efendi J, Smith LM, Wong J (2011) Longitudinal analysis of voluntary adoption of $\mathrm{XBRL}$ on financial reporting. International Journal of Economics and Accounting 2: 173-189.

14. Kim JW, Lim JH, No WG (2012) The effect of first wave mandatory XBRL reporting across the financial information environment. J Inf Syst 26: 127-153.

15. Li CK, Liang D, Lin F, Chen KL (2015) The Application of Corporate Governance Indicators With XBRL Technology to Financial Crisis Prediction. Emerging Markets Finance and Trade 51: S58-S72.

16. Janvrin DJ, No WG (2012) XBRL implementation: A field investigation to identify research opportunities. J Inf Syst 26: 169-197.

17. Bartley J, Chen AYS, Taylor EZ (2011) A comparison of XBRL filings to corporate $10-K s-E v i d e n c e$ from the voluntary filing program. Accounting Horizons 25: 227-245.

18. Russo JE (1977) The value of unit price information. J Mark Res 14: 193-201.

19. Pinsker R, Li S (2008) Costs and benefits of XBRL adoption: early evidence. Commun ACM 51: 47-50

20. Hunton JE, McEwen RA (1997) An assessment of the relation between analysts' earnings forecast accuracy, motivational incentives and cognitive information search strategy. Account Rev 72: 497-515.

21. Frederickson JR, Miller JS (2004) The effects of pro forma earnings disclosures on analysts' and nonprofessional investors' equity valuation judgments. Account Rev 79: 667-686.

22. Schrand C, Verrecchia RE (2004) Disclosure choice and cost of capital: evidence from underpricing in initial public offerings. 
Citation: Tzu-Yi F, Fengyi L, Shih-Hsuan C, Kwo-Liang C (2016) Does XBRL Adoption Imporve Information Asymmetry ? Evidence from Taiwan Public Companies. J Glob Econ 4: 172. doi:10.4172/2375-4389.1000172

23. Leuz C, Verrecchia RE (2000) The economic consequences of increased disclosure. J Account Res 38: 91-124.

24. Mohd E (2005) Accounting for software development costs and information asymmetry. Account Rev 80: 1211-1231.

25. Boone JP (1998) Oil and gas reserve value disclosures and bid-ask spreads. J Account Public Policy 17: 55-84.

26. SEC (U.S. Securities and Exchange Commission) (2009) The investor's advocate: how the SEC protects investors, maintains market integrity, and facilitates capital formation.

27. Clarke J, Shastri K (2000) On information asymmetry metrics. Social Sciences Research Network.

28. Aitken M, Frino A (1996) The determinants of market bid ask spreads on the Australian Stock Exchange: cross-sectional analysis. Account Finance 36: 51-63.

29. Stoll HR (1989) Inferring the components of the bid-ask spread: theory and empirical tests. J Finance 44: 115-134.

30. Copeland TE, Galai D (1983) Information effects on the bid-ask spread. J Finance 38: 1457-1469.
31. Brown S, Hillegeist SA, Lo K (2004) Conference calls and information asymmetry. J Account Econ 37: 343-366.

32. Easley D, Hvidkjaer S, O'hara M (2002) Is information risk a determinant of asset returns? J Finance 57: 2185-2221.

33. Amihud $\mathrm{Y}$, Mendelson $\mathrm{H}$ (1986) Asset pricing and the bid-ask spread. J Financ Econ 17: 223-249.

34. Glosten LR, Harris LE (1988) Estimating the components of the bid/ask spread. J Financ Econ 21: 123-142.

35. Venkatesh $P$, Chiang $R$ (1986) Information asymmetry and the dealer's bid-ask spread: a case study of earnings and dividend announcements. J Finance 41 : 1089-1102.

36. Welker M (1995) Disclosure policy, information asymmetry and liquidity in equity markets. Contemp Account Res 11: 801-827.

37. Greenstein M, Sami H (1994) The impact of the SEC's segment disclosure requirement on bid-ask spreads. Account Rev 69: 179-199.

38. Hasbrouck J (1991) Measuring the information content of stock trades. J Finance 46: 179-207. 